\title{
Growth promoting in vitro effect of synthetic cyclic RGD-peptides on human osteoblast-like cells attached to cancellous bone
}

\author{
URSULA MAGDOLEN $^{1}$, JÖRG AUERNHEIMER ${ }^{3}$, CLAUDIA DAHMEN ${ }^{3}$, \\ JOHANNES SCHAUWECKER ${ }^{1}$, HANS GOLLWITZER ${ }^{1}$, JUTTA TÜBEL ${ }^{1}$, REINER GRADINGER ${ }^{1}$, \\ HORST KESSLER $^{3}$, MANFRED SCHMITT ${ }^{2}$ and PETER DIEHL ${ }^{1}$ \\ ${ }^{1}$ Department of Orthopedic Surgery, and ${ }^{2}$ Clinical Research Unit, Department of Obstetrics and Gynecology, \\ Ismaninger Str. 22, D-81675 Muenchen; ${ }^{3}$ Department Chemie, Technische Universitaet Muenchen, \\ Lichtenbergstrasse 4, D-85747 Garching, Germany
}

Received December 28, 2005; Accepted February 10, 2006

\begin{abstract}
In tissue engineering, the application of biofunctional compounds on biomaterials such as integrin binding RGDpeptides has gained growing interest. Anchorage-dependent cells like osteoblasts bind to these peptides thus ameliorating the integration of a synthetic implant. In case sterilized bone grafts are used as substitutes for reconstruction of bone defects, the ingrowth of the implanted bone is often disturbed because of severe pretreatment such as irradiation or autoclaving, impairing the biological and mechanical properties of the bone. We report for the first time on the in vitro coating of the surface of freshly resected, cleaned bone discs with synthetic, cyclic RGD-peptides. For this approach, two different RGD-peptides were used, one containing two phosphonate anchors, the other peptide four of these binding moieties to allow efficient association of these reactive RGD-peptides to the inorganic bone matrix. Human osteoblast-like cells were cultured on RGD-coated bone discs and the adherence and growth of the cells were analyzed. Coating of bone discs with RGD-peptides did not improve the adhesion rate of osteoblast-like cells to the discs but significantly (up to $40 \%$ ) accelerated growth of these cells within 8 days after attachment. This effect points to pretreatment of bone implants, especially at the critical interface area between the implanted bone and the non-resected residual bone structure, before re-implantation in order to stimulate and enhance osteointegration of a bone implant.
\end{abstract}

Correspondence to: Dr Ursula Magdolen, Orthopaedische Klinik und Poliklinik der Technischen Universitaet Muenchen, Ismaninger Str. 22, D-81675 Muenchen, Germany

E-mail: ulla.magdolen@1rz.tum.de

Key words: human bone, osteoblast-like cells, RGD-peptide, cell growth, cell adherence

\section{Introduction}

Reconstruction of major bone defects with bone grafts requires sterilization of the implant prior to implantation. Very stringent treatment of the bone is demanded when allografts are used in order to destroy potential contaminations by viruses, bacteria, or prion proteins. Also, when autologous tumorbearing resected bone segments are chosen for reconstruction of defects complete elimination of tumor cells is needed. Different devitalization procedures such as autoclaving, irradiation, and chemical treatment are in use but all of them deteriorate the biomechanical and biological properties of the bone (1-3). Thus, the integration of the implant is often obstructed, leading to a delayed healing process (4-7). An alternative to these methods of bone sterilization is under pre-clinical testing, the application of very high hydrostatic pressure to destroy germs and tumor cells in resected bone segments (8-10). With this method at pressure values as high as $600 \mathrm{MPa}$ tumor cells are destroyed while the biomechanical and biological properties of bone are preserved $(11,12)$.

The biofunctionalization of implant material is of growing interest in implantology with the goal to improve integration of synthetic prostheses, but the same may apply to bone sterilized in different ways. For the coating of metallic or polymeric implant surfaces, adhesion promoting proteins such as fibronectin, vitronectin, collagen I, or synthetic RGDpeptides representing the cell-binding domain of these extracellular matrix proteins are used (13-17).

We are extending such studies to freshly resected, cleaned bone with the intention of re-implantation into the patient. We report for the first time on the clinical relevant effect of adherence and growth of osteoblast-like cells on freshly resected human bone coated with synthetic, cyclic RGDpeptides prior to implantation. To achieve this goal in a preclinical test setting, freshly resected, cleaned human bone was treated with synthetic cyclic RGD-peptides containing a spacer entity and a reactive anchor moiety for attachment to the calcium constituent of the bone mineral matrix. Such a cyclo(-RGDfK-) peptide strongly interacts with the $\alpha_{v^{-}}$ 


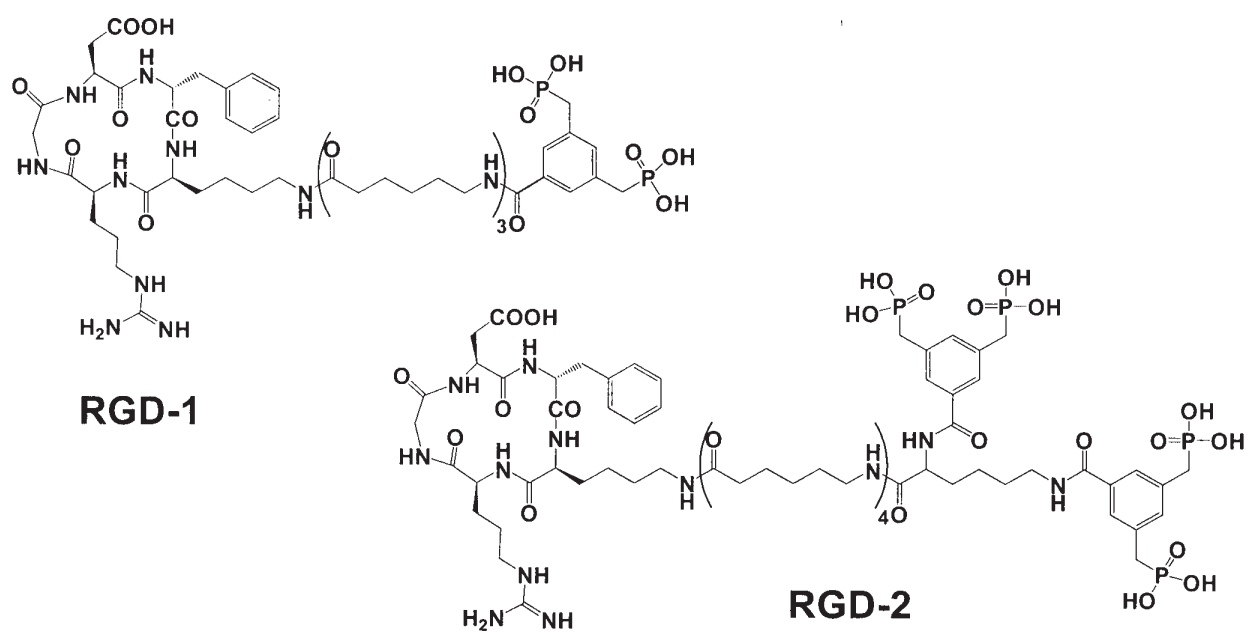

Figure 1. Cyclic RGD-peptides (RGD-1, RGD-2) with phosphonic acid anchors and spacer groups. Synthetic cyclic pentapeptides containing the RGD(Asp-GlyArg)-sequence serving as highly active and selective ligands for the $\alpha_{v} \beta_{3} / \alpha_{v} \beta_{3}$ integrins. The peptides are bridged by a spacer of three and four $\varepsilon$-aminohexanoic acids, respectively and coupled to a phosphonic acid surface anchor.

subunit of $\alpha_{v} \beta_{3}$ and $\alpha_{v} \beta_{5}$ integrins $(18,19)$ and to lesser extent with the $\alpha$ IIbß3 integrin (20). The $\alpha_{v}$-subunits of $\alpha_{v} \beta_{3}$ and $\alpha_{v} \beta_{5}$ integrins are important functional integrins of osteoblasts and mediate cell-matrix adhesion, cell proliferation and cell differentiation (16).

In this study, we report for the first time on the effect of adherence and growth of osteoblast-like cells on freshly resected human bone coated with synthetic, cyclic RGDpeptides. This approach is of clinical relevance with the goal to improve integration of sterilized allogenic or autologous bone grafts by fast coating with cyclic RGD-peptides prior to implantation.

\section{Materials and methods}

Preparation of RGD-peptides. Cyclic RGD-peptides derivatized with a phosphonic acid anchor were synthesized as described by Auernheimer and Kessler (21). Briefly, the linker was synthesized by standard solid phase peptide synthesis using the TCP-resin (22) applying the Fmoc(9-fluorenylmethoxycarbonyl) strategy (23). The resin was loaded with $\mathrm{N}$-Fmoc6-aminohexanoic acid, followed by subsequent coupling of three $N$-Fmoc-6-aminohexanoic acids (RGD-1) and $N, N$ '-BisFmoc-lysine (RGD-2), respectively. The phosphonate moiety was introduced as 5-carboxy- $m$-xylene-bis-phosphonic acid tetrabenzylester. The linker was detached from the resin by acetic acid/ $\mathrm{CH}_{2} \mathrm{Cl}_{2} /$ trifluorethanol (3:6:1). Afterwards the linker was coupled to the partially protected cyclic pentapeptide cyclo(-R(2,2,4,6,7-pentamethyldihydrobenzofuran5-sulfonyl)GD(tert.-butylester)fK-) (24) using HATU ( $O$ (7-azabenzotriazol-1-yl)- $N, N, N^{\prime}, N^{\prime}$-tetramethyluroniumhexafluorophosphate), HOAt (1-hydroxy-7-azabenzo-triazol) and collindine in DMF ( $N, N$-dimethylformamide). After deprotection with TFA (trifluoroacetic acid), the peptides (Fig. 1) were purified by RP-HPLC.

Cell culture. Primary human osteoblast-like cells were isolated from cancellous bone originating from patients undergoing hip replacements. Only bone which would otherwise have been discarded was used and its collection and use for scientific purposes was approved by the local Ethics Committee. Cleaned and minced bone fragments were cultured in $75 \mathrm{~cm}^{2}$ tissue culture flasks (Falcon, Becton-Dickinson, NJ, USA) in calcium-free Dulbecco's modified Eagle's medium (DMEM, Biochrom KG, Berlin, Germany) supplemented with heat-inactivated $10 \%$ fetal bovine serum (FBS), $2 \mathrm{mM}$ glutamine, $1 \%$ penicillin and streptomycin, and MEM-vitamins (Biochrom) at $37^{\circ} \mathrm{C}$ in a humidified atmosphere containing $5 \% \mathrm{CO}_{2}$. For the experiments, medium was supplemented with $50 \mu \mathrm{g} / \mathrm{ml}$ ascorbic acid (Sigma-Aldrich, Steinheim, Germany) and $4 \mathrm{ng} / \mathrm{ml}$ dexamethasone (Sigma-Aldrich). Passages 2-4 of the cultures were used and cells of 4 patients pooled to level out individual variances. The osteoblastic phenotype of the cultured cells was confirmed by histologic staining for alkaline phosphatase and collagen type I.

Preparation and RGD-coating of bone discs. Cylindrical bone specimens ( $7 \mathrm{~mm}$ in diameter) were punched out of cancellous human femoral heads and cut into 2-3 mm thick discs. Pieces were washed 3 times in PBS (phosphate-buffered saline) for $1 \mathrm{~h}$ at $37^{\circ} \mathrm{C}$ to remove single cells, and soluble tissue-derived components. Next, to remove fat, bone discs were incubated in acetone overnight at room temperature and then air-dried for $24 \mathrm{~h}$ in a sterile bench. Afterwards these bone discs were washed for $1 \mathrm{~h}$ in $0.1 \mathrm{M}$ Tris-HCl, pH $7.0(1 \mathrm{~h}, \mathrm{RT})$ and then incubated with either $100 \mu \mathrm{M}$ of RGD-1 or RGD-2 solution overnight at $4^{\circ} \mathrm{C}$. As a control, untreated bone pieces were incubated in $0.1 \mathrm{M}$ Tris- $\mathrm{HCl}, \mathrm{pH} 7.0$, only. The following day all bone discs were washed three times with $0.1 \mathrm{M}$ Tris- $\mathrm{HCl}$, $\mathrm{pH} 7.0$, and placed into wells of a 48-well tissue culture plate (Falcon).

Cultivated osteoblast-like cells obtained from human cancellous bone were detached from the cell culture flask surface by treatment with $0.01 \%$ (w/v) trypsin EDTA solution (Gibco, Invitrogen, UK), harvested by centrifugation, and washed in PBS. The cells were resuspended in serum-free 


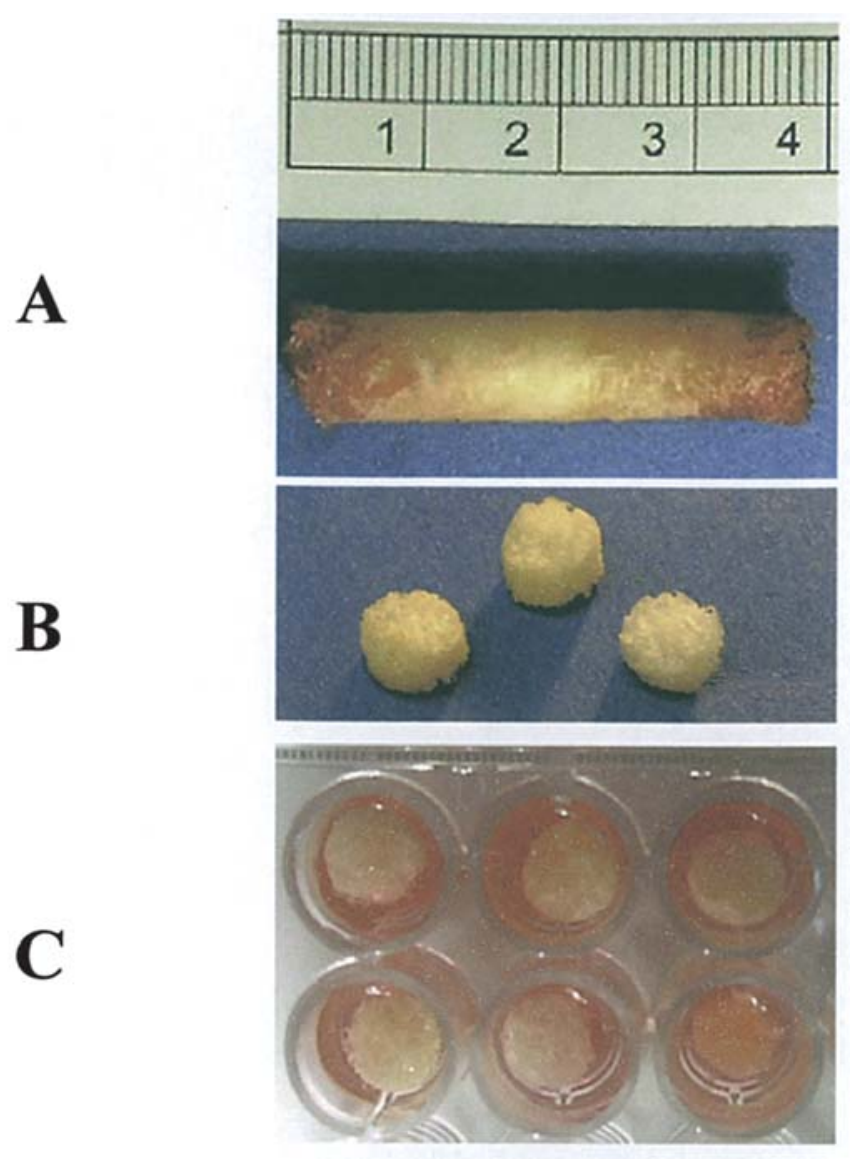

Figure 2. Bone discs prepared from human cancellous bone. Cylindrical core biopsies (A) were taken from femoral heads and cut into slices of 2-3 mm thickness (B). After extensive washing of these bone discs with PBS and acetone to remove cells, soluble proteins, and fat, discs were coated with cyclic RGD-peptides $(100 \mu \mathrm{M})$ overnight at $4^{\circ} \mathrm{C}$. Subsequently, they were washed three times in $0.1 \mathrm{M}$ Tris- $\mathrm{HCl}, \mathrm{pH} 7.0$, at room temperature and used for cell experiments in 48 -well microplates (C).

medium supplemented with 1\% BSA (Sigma-Aldrich) as bovine serum may contain considerable amounts of the endogenous RGD-containing ECM proteins fibronectin and vitronectin. Cells $(\sim 10,000)$ in $50 \mu 1$ serum-free DMEM/1\% BSA were applied to the surface of each bone piece and left for $30 \mathrm{~min}$ at $37^{\circ} \mathrm{C}$ to allow adherence to the bone discs; then the wells were filled with $400 \mu 1$ of serum-free DMEM/1\% BSA and incubated for $24 \mathrm{~h}$ at $37^{\circ} \mathrm{C}$. At the end of the incubation period, the bone discs were washed three times with PBS. The amount of adherent cells was quantified by determination of lysosomal hexosaminidase activity using a colorimetric assay according to the procedure of Landegren (25). For control adhesion experiments, small plates $(7 \times 7 \mathrm{~mm})$ of titanium alloy (TiAl6Nb7, Firma Keller, Straubing, Germany) in 96square-well plates (Whatman Inc., Clifton, NJ, USA), were coated with the two RGD-peptides the same way as described for the bone fragments.

For determination of long-term settling of cells, $10 \%$ fetal bovine serum containing medium (Biochrom) was added to the wells after a 24-h adhesion period and incubation continued for additional 8 days before the number of adherent cells was determined by use of the hexosaminidase assay (25).

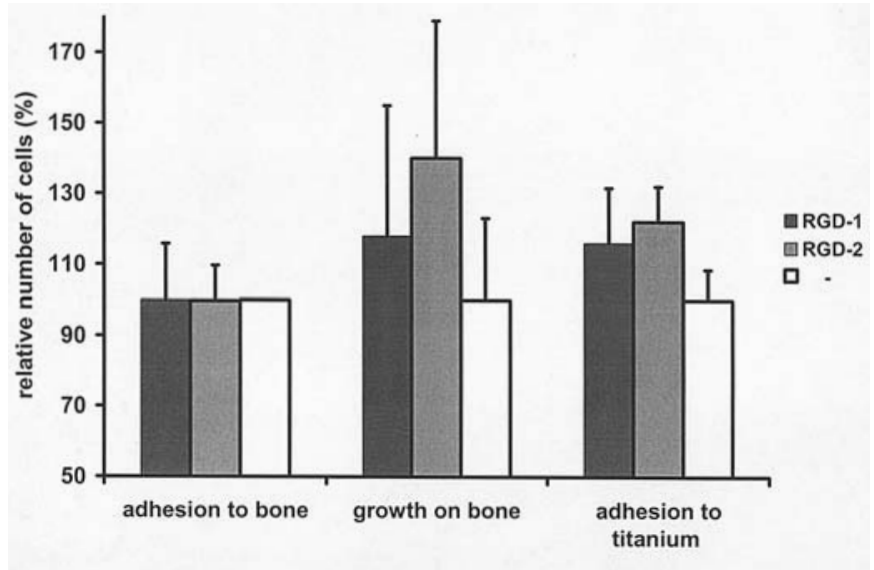

Figure 3. Adhesion and growth of osteoblast-like cells on RGD-coated bone discs and small titanium alloy plates. 10,000 cells in $50 \mu 1 \mathrm{DMEM} / 1 \%$ BSA were applied to the surface of every bone piece (in a 48-well microplate) or a titanium alloy small plate (TiAl6 Nb7, in a 96-well square well plate). For adhesion experiments, the amount of adherent cells was examined after $24 \mathrm{~h}$, for determination of growth after 8 additional days. The data presented are mean values (with standard deviations) of nine independent growth experiments, of four independent adhesion experiments (bone), and two adhesion experiments (titanium alloy). The number of adherent cells was quantified by the lysosomal hexosaminidase assay and uncoated controls were set to $100 \%$.

\section{Results and Discussion}

RGD-peptides were employed as adhesion promoters to condition synthetic implant materials such as titanium, hydroxyapaptite, and polymethylmethacrylate (PMMA) (26-34). Until now, derivatization of native bone with RGDpeptides and effects on proliferation and adherence of osteoblast-like cells attached to RGD-peptide-coated human bone have not been described. The synthetic, cyclic RGDpeptides (Fig. 1) we used display unique and enhanced stability in vivo compared to linear RGD-peptides and are not degraded by human proteases. Moreover, these synthetic RGD-peptides contain phosphonate anchor groups which efficiently react with the inorganic bone matrix to form stable bone-RGD-peptide constructs. In essence, human cancellous bone disks were cut from hip bone (Fig. 2), cleaned and defatted by acetone, similar to the procedure applied for chemical sterilization of bone used in the preparation of allogenic and autologous bone grafts (35). These bone discs were subjected to coating with two types of cyclic RGDpeptides, differing only by the number of phosphonate anchor groups, with the aim to enhance the rate of adhesion and proliferation of osteoblast-like cells. The cultivation of osteoblast-like cells on RGD-coated bone discs was performed for 8 days before the number of attached cells was analyzed by determination of the lysosomal enzyme hexosaminidase, an indirect measure of cell number (25).

We found a significantly higher growth of cells on RGDcoated bone discs, $18 \%$ more for RGD-1 and 40\% more for RGD-2, compared to non-treated control bone discs (Fig. 3). Interestingly, this enhanced settlement rate is not due to a higher initial adhesion rate, as the amount of attached cells at the beginning is not increased on RGD-coated bone discs compared to uncoated controls. 
Interaction of cells with ECM proteins or synthetic RGDpeptides is mediated by integrins, transmembrane protein receptors that control cell functions such as cell-matrix adhesion and cell proliferation (36,37). The synthetic, cyclic RGD-peptides we applied are selective for binding of $\alpha_{\mathrm{v}}$ containing integrins; therefore, upon cell binding, they mimic the effects of the multifunctional RGD-peptide containing the ECM proteins fibronectin and vitronectin (38). Evidently, the stimulation of long-term settlement of osteoblast-like cells is more effective for RGD-2 than for RGD-1. In this respect, it is worth mentioning that peptide RGD-2 contains four phosphonate anchors and therefore provides stronger anchoring to the inorganic bone matrix than RGD-1 which contains only two phosphonates.

Pretreatment of native bone with the RGD-peptides did not lead to enhanced adhesion of osteoblast-like cells to the modified bone discs compared to untreated bone (Fig. 3). This result may be due to the fact that pre-treatment of the bone with phosphate buffer and the organic solvent acetone removes water-soluble and fatty components but leaves the insoluble collagen I matrix intact. Collagen I is a major structural protein of the bone and allows adhesion of cells to the bone matrix even when the collagen is denatured. Therefore, it can be assumed that binding of the osteoblastlike cells to the collagen I containing bone matrix does occur by activation and rearrangement of the $\alpha$ and $\beta$ subunits of integrins, e.g. by forming $\beta$-homotrimers $(39,40)$. As enough binding sites are provided by the collagen I matrix of the bone, the additionally provided synthetic RGD-peptides most probably are not relevant for cell attachment. This observation is in agreement with the data of Rezania and Healy (37) showing that the initial adhesion of osteoblast-like cells to RGD-containing surfaces is mainly due to $\alpha_{2} \beta_{1}$-integrin interaction, which is a collagen I-receptor. In contrast to this disapproving effect of RGD-peptides in the initial phase of the adhesion experiments, we observed a long-term growthstimulating effect on the osteoblast-like cells during the 8day cultivation period of attachment to RGD-peptide-coated, fibronectin-mimicking surface in relation to the non-coated control bone discs. Interestingly, this finding is in agreement with studies by Cowles et al (41) and Geissler et al (42) who showed improved cell proliferation on fibronectin-coated surfaces compared to collagen I only exposing matrices.

To further substantiate our findings, experiments were conducted with small plates of titanium alloy coated with RGD-1 and RGD-2 peptides. The positive effect of precoating of synthetic metal implant material with cyclic RGD-peptides on osteoblast-like cell adhesion was demonstrated (Fig. 3). Corresponding experiments with mouse osteoblasts gave similar results (21).

Our data provide evidence that RGD-coating positively stimulated the growth of osteoblast-like cells attached to native human bone. This finding opens a new vista to a convenient method of conditioning the surface of any kind of bone graft prior to implantation, thus promoting an improved and earlier integration of a resected bone implant in vivo. For optimal accessability of the inorganic bone matrix to the RGD-peptides, a cleaning step to remove tissue debris and fatty components from the bone graft surface is advised. A gentle cleaning procedure for autologous bone grafts might be ultrasonication which was shown to efficiently clean bone pieces before cultivation with osteoblast-like cells (43).

We would like to stress that endothelial cells bind to RGD-motifs as well (44). Therefore, we expect that RGDcoating of bone matrices does promote neovascularization, a precondition for osteointegration after bone implantation.

We conclude that coating of native human bone with synthetic, cyclic small size RGD-peptides stimulates in vitro growth of human osteoblast-like cells attached to this modified bone surface. Therefore, it is intriguing to speculate that coating of bone implants with RGD-peptides prior to reimplantation could serve as a novel approach to accelerate the in-growth and healing of a bone implant.

\section{Acknowledgements}

This work was supported in part by the Research Network for Tissue Engineering and Rapid Prototyping (Forschungsverbund FORTEPRO, project TE3) of the Bavarian Research Foundation (Bayerische Forschungsstiftung) and Schwerpunktprogramm 1100 of the German Research Association (Deutsche Forschungsgemeinschaft). We would like to acknowledge that the small plates of titanium alloy used in this study were conditioned by Dr S. Guder (Technische Universität München, Fakultät für Maschinenwesen, Garching, Germany).

\section{References}

1. Araki N, Myoui A, Kuratsu S, et al: Intraoperative extracorporeal autogenous irradiated bone grafts in tumor surgery. Clin Orthop 368: 196-206, 1999.

2. Boehm P, Springfeld R and Springer H: Re-implantation of autoclaved bone segments in musculoskeletal tumor surgery: clinical experience in 9 patients followed for 1.1-8.4 years and review of the literature. Arch Orthop Trauma Surg 118: 57-65, 1998.

3. Boehm P, Fritz J, Thiede S and Budach W: Reimplantation of extracorporeal irradiated bone segments in musculoskeletal tumor surgery: clinical experience in eight patients and review of the literature. Langenbecks Arch Surg 387: 355-365, 2003.

4. Hornicek FJ, Gebhardt MC, Tomford WW, Sorger JI, Zavatta M, Menzner JP and Mankin HJ: Factors affecting non-union of the allograft-host junction. Clin Orthop 382: 87-98, 2001.

5. Sorger JI, Hornicek FJ, Zavatta M, Menzner JP, Gebhardt MC, Tomford WW and Mankin HJ: Allograft fractures revisited. Clin Orthop 382: 66-74, 2001.

6. Sugimoto M, Takahashi S, Toguchida J, Kotoura Y, Shibamoto Y and Yamamuro T: Changes in bone after high-dose irradiation biomechanics and histomorphology. J Bone Joint Surg Br 73: 492-497, 1991.

7. Zoricic S, Bobinac D, Lah B, et al: Study of the healing process after transplantation of pasteurized bone grafts in rabbits. Acta Med Okayama 56: 121-128, 2002.

8. Diehl P, Schmitt M, Bluemelhuber G, et al: Induction of tumor cell death by high hydrostatic pressure as a novel supporting technique in orthopedic surgery. Oncol Rep 10: 1851-1855, 2003.

9. Diehl P, Reuning U, Gollwitzer H, et al: Effect of extracorporal high hydrostatic pressure on tumor cell adherence and viability. Oncol Rep 12: 369-373, 2004.

10. Naal F-D, Mengele K, Schauwecker J, et al: High hydrostatic pressure-induced cell death in human chondrocytes and chondrosarcoma cells. Anticancer Res 25: 1977-1982, 2005.

11. Diehl P, Schmitt M, Schauwecker J, et al: Effect of high hydrostatic pressure on biological properties of extracellular bone matrix proteins. Int J Mol Med 16: 285-289, 2005. 
12. Steinhauser E, Diehl P, Hadaller M, Schauwecker J, Busch R, Gradinger R and Mittelmeier W: Biochemical investigation of the effect of high hydrostatic pressure treatment on the mechanical properties of human bone. J Biomed Mater Res 76B: 130-135, 2006.

13. Anselme K: Osteoblast adhesion on biomaterials. Biomaterials 21: 667-681, 2000.

14. Hersel U, Dahmen C and Kessler H: RGD modified polymers: biomaterials for stimulated cell adhesion and beyond. Biomaterials 24: 4385-4415, 2003

15. Shin H, Temenoff JS, Bowden GC, Zygourakis K, FarachCarson MC, Yaszemski MJ and Mikos AG: Osteogenic differentiation of rat bone marrow stromal cells cultured on Arg-GlyAsp modified hydrogels without dexamethasone and betaglycerol phosphate. Biomaterials 26: 3645-3654, 2005.

16. Schaffner P and Dard MM: Structure and function of RGD peptides involved in bone biology. Cell Mol Life Sci 60: 119-132, 2003.

17. Auernheimer J, Zukowski D, Dahmen C, Kantlehner M, Enderle A, Goodman L and Kessler H: Titanium implant materials with improved biocompatibility via coating with phosphonate-anchored cyclic RGD-peptides. Chembiochem 6 : 2034-2040, 2005.

18. Pfaff M, Tangemann K, Mueller B, et al: Selective recognition of cyclic RGD peptides of NMR defined conformation by alpha IIb beta 3, alpha V beta 3, and alpha 5 beta 1 integrins. J Biol Chem 269: 20233-20238, 1994.

19. Haubner R, Gratias R, Diefenbach B, Goodman SL, Jonczyk A and Kessler H: Structural and functional aspects of RGDcontaining cyclic pentapeptides as highly potent and selective integrin $\alpha_{\mathrm{v}} \beta_{3}$ antagonists. J Am Chem Soc 118: 7461-7472, 1996

20. Aumailley M, Gurrath M, Müller G, Calvete J, Timpl R and Kessler H: Arg-Gly-Asp constrained within cyclic pentapeptides strong and selective inhibitors of cell adhesion to vitronectin and laminin fragment P1. FEBS Lett 291: 50-54, 1991.

21. Auernheimer J and Kessler H: Benzylprotected aromatic phosphonic acids for anchoring peptides on titanium. Bioorg Med Chem Lett 16: 271-273, 2005

22. Barlos K, Gatos D, Kallitsis J, Papaphotiu G, Sotiru P, Weqing Y and Schäffer W: Darstellung geschützter Peptid-Fragmente unter Einsatz substituierter Triphenylmethyl-Harze. Tetrahedron Lett 30: 3943-3946, 1989.

23. Fields GB and Noble RL: Solid-phase peptide-synthesis utilizing 9-fluorenylmethoxycarbonyl amino-acids. Int J Pept Protein Res 35: 161-214, 1990.

24. Kantlehner M, Schaffner P, Finsinger D, et al: Surface coating with cyclic RGD peptides stimulates osteoblast adhesion and proliferation as well as bone formation. Chembiochem 1: 107-114, 2000.

25. Landegren U: Measurement of cell numbers by means of the endogenous enzyme hexosaminidase. Applications to detection of lymphokines and cell surface antigens. J Immunol Methods 67: 379-388, 1984.

26. Gronowicz G and McCarthy MB: Response of human osteoblasts to implant materials: integrin-mediated adhesion. J Orthop Res 14: 878-887, 1996.

27. Kantlehner M, Finsinger D, Meyer J, et al: Adhesion of osteoblasts at surfaces of implants. Angew Chem Int Ed Engl 38: 560-562, 1999.
28. Schaffner P, Meyer J, Dard M, et al: Induced tissue integration of bone implants by coating with bone selective RGD-peptides in vitro and in vivo studies. J Mater Sci Mater Med 10: 837-839, 1999.

29. Ferris DM, Moodie GD, Dimond PM, Gioranni PM, Ehrlich MG and Valentini RF: RGD-coated titanium implants stimulate increased bone formation in vivo. Biomaterials 20: 2323-2331, 1999.

30. Jeschke B, Meyer J, Jonczyk A, et al: RGD-peptides for tissue engineering of articular cartilage. Biomaterials 23: 3455-3463, 2002.

31. Schliephake H, Scharnweber D, Dard M, Rössler S, Sewing A, Meyer J and Hoogestraat D: Effect of RGD peptide coating of titanium implants on peri-implant bone formation in the alveolar crest. An experimental pilot study in dogs. Clin Oral Impl Res 13: 312-319, 2002.

32. Dahmen C, Auernheimer J, Meyer A, Enderle A, Goodman SL and Kessler H: Improving implant materials by coating with non-peptidic, highly specific integrin ligands. Angew Chem Int Ed Engl 43: 6649-6652, 2004.

33. Elmengaard B, Bechtold JE and Søballe K: In vivo study of the effect of RGD treatment on bone ongrowth on press-fit titanium alloy implants. Biomaterials 26: 3521-3526, 2005.

34. Steinhauser E, Liebendörfer A, Enderle A, et al: In vivo-Studie zu knöchernen Integration von RGD-Peptid beschichteten und unbeschichteten metallischen Implantaten. MP Materialprüfung 4: 197-202, 2005.

35. Hofmann A, Hofmann C and Gotzen L: Effect of various bone disinfection and sterilization methods on osteoblast function. A comparative in vitro study. Unfallchirurg 103: 380-388, 2000.

36. Longhurst CM and Jennings LK: Integrin-mediated signal transduction. Cell Mol Life Sci 54: 514-526, 1998.

37. Rezania A and Healy KE: Integrin subunits responsible for adhesion of human osteoblast-like cells to biomimetic peptide surfaces. J Orthop Res 17: 615-623, 1999.

38. Wester HJ and Kessler H: Molecular targeting with peptides or peptide-polymer-conjugates: just a question of size? J Nucl Med 6: 1940-1945, 2005

39. Gottschalk KE and Kessler H: A computational model of transmembrane integrin clustering. Structure 12: 1109-1116, 2004.

40. Li W, Metcalf DG, Gorelik R, et al: A push-pull mechanism for regulating integrin function. Proc Natl Acad Sci USA 102: 1424-1429, 2005.

41. Cowles EA, Brailey LL and Gronowicz GA: Integrin-mediated signaling regulates AP-1 transcription factors and proliferation in osteoblasts. J Biomed Mater Res 52: 725-737, 2000.

42. Geissler U, Hempel U, Wolf C, Scharnweber D, Worch H and Wenzel K: Collagen type I-coating of Ti6Al4V promotes adhesion of osteoblasts. J Biomed Mater Res 51: 752-760, 2000.

43. Schauwecker J, Diehl P, Bauer D, et al: High hydrostatic pressure treatment of bone tissue with subsequent revitalization. Biomaterialien 6: 125, 2005.

44. Holland J, Hersh L, Bryhan M, Onyiriuka E and Ziegler L: Culture of human vascular endothelial cells on an RGD-containing synthetic peptide attached to a starch-coated polystyrene surface: comparison with fibronectin-coated tissue grade polystyrene. Biomaterials 17: 2147-2156, 1996. 